\title{
Early Evidence of Circulating SARS-CoV-2 in Unvaccinated and Vaccinated Measles Patients, September 2019-February 2020
}

\author{
Joana Paixao (DID ${ }^{1,2}$, Maria Galangue', Celestina Gaston', Raísa Carralero', Celestina Lino', \\ Gracieth Júlio', Zinga David', Moises Francisco', Cruz S Sebastião' ${ }^{1,3,4}$, Euclides NM Sacomboio ${ }^{1,4}$, \\ Joana Morais ${ }^{1,5}$, Ngiambudulu M Francisco (D)
}

'Grupo de Investigação Microbiana e Imunológica, Instituto Nacional de Investigação em Saúde (National Institute for Health Research), Luanda, Angola; ${ }^{2}$ Unidade de Ensino e Investigação de Microbiologia Médica, Instituto de Higiene e Medicina Tropical, Universidade Nova de Lisboa, Lisboa, Portugal; ${ }^{3}$ Centro de Investigação em Saúde de Angola, Luanda, Angola; ${ }^{4}$ Instituto Superior de Ciências de Saúde, Universidade Agostinho Neto, Luanda, Angola; ${ }^{5}$ Faculdade de Medicina, Universidade Agostinho Neto, Luanda, Angola

Correspondence: Ngiambudulu M Francisco, Grupo de Investigação Microbiana e Imunológica, Instituto Nacional de Investigação em Saúde (National Institute for Health Research), Rua: Amílcar Cabral, No. 96, por trás do Hospital Josina Machel, P.O. Box: 3635, Luanda, Angola, Tel +244 93I 36 I7I7, Email franciscongiamb@yahoo.com

Background: The global emergence of coronavirus disease 2019 (COVID-19) has challenged healthcare and rapidly spread over the globe. Early detection of new infections is crucial in the control of emerging diseases. Evidence of early recorded COVID-19 cases outside China has been documented in various countries. In this study, we aimed to identify the time of SARS-CoV-2 infection circulation by retrospectively analyzing sera of measles patients, weeks before the reported first COVID-19 cases in Angola.

Materials and Methods: We examined the humoral response against SARS-CoV-2 by using an enzyme-linked immunosorbent assay (ELISA)-based assay on a combined two-step sandwich enzyme immunoassay method. In total, we received 568 study patients with blood specimens collected from 23 September 2019 to 28 February 2020, 442 sera samples that met the criteria of the study were withdrawn and selected from the overall 568 received samples. In this study, we considered seropositives, patients who tested positive for SARS-CoV-2 immunoglobulin G (IgG) and M (IgM) antibodies with the index value $>1$.

Results: Of the 442 sera samples that met the criteria of the study, 204 were measles seropositive. Forty out of 204 were confirmed reactive to SARS-CoV-2 viral proteins using IgG and IgM more than 2 weeks before the first reported case in Angola. The humoral response analysis showed significant differences $(p=0.01)$ between the $\operatorname{IgG}$ and $\operatorname{IgM}$ indexes in the unvaccinated measles patients. Similarly, a significant difference $(p=0.001)$ was seen between the IgG and $\operatorname{IgM}$ indexes in the vaccinated measles patients.

Conclusion: Here, using the humoral response analysis, we report the identification of early circulation SARS-CoV-2 infection weeks before the first recognized cases in the Republic of Angola.

Keywords: infection, antibodies, pandemic, COVID-19, humoral response

\section{Introduction}

The first case of severe acute respiratory syndrome coronavirus 2 (SARS-CoV-2), the virus that causes the novel coronavirus disease 2019 (COVID-19), was reported in Wuhan City, Hubei's Province of China, with notification to the World Health Organization (WHO) on 31 December 2019. ${ }^{1}$

Since then, the outbreak of COVID-19 rapidly spread to produce a global pandemic and is now considered a public health challenge. The gaps in early testing may have led to a widespread underestimation of infected individuals. In order to better prepare for the next major outbreak, a more detailed and thorough understanding of the early emergence of this pandemic is required. Evidence of early recorded COVID-19 cases outside China have been documented in various countries, and a number of strategies have been used to estimate the insurgence of SARS-CoV-2, including early 
phylogenetic analyses and clinical biological sample testing, suggesting that SARS-CoV-2 may have evolved earlier between October and December 2019. ${ }^{2-6}$

To that end, we performed a retrospective analysis on the epidemiological vigilance samples from patients who reported to the public medical treatment facilities during the period from 23 September 2019 to 28 February 2020 complaining of measles symptoms. In Angola, the first SARS-CoV-2 infections (two first confirmed cases) were detected at the Instituto Nacional de Investigação em Saúde (National Institute for Health Research) ${ }^{7}$ and reported by the Angolan Health Minister on 21 March 2020. SARS-CoV-2 rapidly spread after introduction into low-resourced population areas due to the lack of hygienic and personal protection measures, resulting in significant morbidity and mortality cases that may lead to the increased burden on country health care systems ${ }^{8}$ and crumble the economy. On February 14, 2020, the Egyptian Ministry of Health confirmed that a 33-year-old man, of foreign origin, was diagnosed with SARS-CoV-2; this is the first case from Africa. The second day occurred on the February 25, 2020, when the Ministry of Health, Population and Hospital Reform of Algeria has reported the country's first case of COVID-19. On March 5, 2020, the South African National Institute for Communicable Diseases reported that a suspected 38-year-old man who travelled to Italy has tested COVID-19 positive. This made South Africa the First Southern African country to report COVID-19. Since then, South Africa has become the leading country with regard to COVID-19 cases. While other continents have reported a dramatic number of COVID-19 cases or found evidence of early circulating SARSCoV-2 earlier than had initially been reported, ${ }^{9-11}$ until February 14, 2020, Africa was still reporting imported cases of COVID-19. Early detection of new infections is crucial in the control of emerging disease. With regard to the COVID19 pandemic, retrospective serological testing has shown to increase results obtained from testing archived by respiratory specimens with molecular methods, when trying to identify the insurgence of SARS-CoV-2 into a population. Serological testing is now widely used to detect viruses, including for HIV, ${ }^{12}$ and it can estimate the introduction of viral infections into populations. ${ }^{6}$ Blood sample specimens from measles patients from all provinces, except Lunda Sul's Province were sent to the National Institute for Health Research in Luanda, Angola, starting from 23 September 2019 to 28 February 2020, with a purpose of measles epidemiological vigilance analysis. We then, retrospectively tested these samples for SARS-CoV-2-reactive antibodies. In this report, we aimed to investigate the time of SARS-CoV-2 infection circulation in Angola, by retrospectively analyzing antibodies in the sera of measles patients who were referred to the National Institute for Health Research as part of epidemiological surveillance of neglected diseases.

\section{Methods}

\section{Study Oversight}

The Angolan Ministry of Health has adopted the epidemiological surveillance strategy that requires all suspected cases with emerging diseases to be confirmed at the National Institute for Health Research and has given this institute the mandate to further investigate any case of interest. During the period of 23 September 2019 to 28 February 2020, a total of 568 full blood samples, presumably for measles disease from all provinces of Angola (except one province that did not report the epidemiological surveillance case), were sent to the National Institute for Health Research for diagnostic confirmation.

Briefly, a volume of $4 \mathrm{~mL}$ of full blood was collected from these patients and sent to the National Institute for Health Research, accompanied by the medical report form. At the arrival, new Laboratory numbers were assigned for each sample and anthropometric and sociodemographic information were recorded. Full blood samples were centrifuged, sera were collected and stored at $-40{ }^{\circ} \mathrm{C}$ in the freezer, and stored sera were referred to as measles national database of the measles epidemiological notification samples. Thus, our study samples were taken from the stored national database of the measles epidemiological notification samples used for epidemiological surveillance between September 2019 to February 2020. Prior to blood collection, children's parents or adult patients were informed about the nature of the analysis that will be performed on their samples and agreed after the informed consent process was explained to them at their respective public health treatment facilities. 
For this retrospective serologic study, a total of 442 sera samples that met the criteria of the study were withdrawn and selected from the overall 568 received samples. We recorded the date of specimen collection and arrival of samples, province of residence, and socio-demographic characteristics of study participants of those who met our definition of seropositive using the sequential testing algorithm. Sera were extracted and stored at $-40^{\circ} \mathrm{C}$ until use. A total of 126 participants were not included in this study, because of incomplete information or samples with the formation of fibrin with micro-clots that were visible to the naked eyes, since the presence of fibrin can lead to erroneous results. We withdrew frozen serum specimens from our measles biorepository and prepared for serologic testing, starting with specimens collected in approximately 6 months intervals from 23 September 2020, moving backward in time until there were no positive specimens yet reported in the country. The sensitivity, specificity, and Clopper-Pearson exact binomial 95\% confidence intervals (CIs) were estimated for VIDAS ${ }^{\circledR}$ SARS-COV-2 IgG and IgM ELISA, using blinded positive control specimens from individuals who were hospitalized or discharged and convalescing with molecular test real timepolymerase chain reaction (RT-PCR), confirming SARS-CoV-2 infection. Our negative control specimens came from previously stored blood donors who reported at the Instituto Nacional de Sangue, in Luanda Angola.

We used the reference database provided by SGVFinder, which is based on the proGenomes database (http:// progenomes1.embl.de/).

To test the cross-reactivity and competition of antibody class specificity between IgM and $\operatorname{IgG}$ we used the instrument Biomérieux VIDAS ${ }^{\circledR}$. We proceeded with the cross-reaction by analyzing five negative samples in duplicate, thereafter were spiked with $10 \mu \mathrm{g} / \mathrm{mL}$ of a recombinant human monoclonal $\mathrm{IgG}$ (rec Hu mAb IgG) anti-SARS-CoV-2 and tested again in duplicate. All IgG spiked samples showed negative results with the VIDAS ${ }^{\circledR}$ SARS-CoV-2-IgM test. For the competition test, also five IgM-positive samples with various levels of index values were tested in duplicate, then were spiked with $10 \mu \mathrm{g} / \mathrm{mL}$ of rec $\mathrm{Hu} \mathrm{mAb}$ IgG anti-SARS-CoV-2 and were tested in duplicate. For both negative and positive sets of samples, an agreement of $100 \%$ was obtained between control and spiked samples, as described by manufacturer's protocol (www.biomerieux.com/techlib). This study was conducted in accordance with the declaration of Helsinki.

\section{Antibody Assays}

The testing was performed in the immunoserology Laboratory of the National Institute for Health Research, because of the COVID-19 contingency plan implemented and the re-structuration of the Laboratory at our Institute, testing of study samples began in April 2021 and continued through July 2021. We used the Biomérieux VIDAS ${ }^{\circledR}$ SARS-COV-2 IgG and IgM enzymelinked immunosorbent assay (ELISA), and results were analyzed as they were completed. SARS-CoV-2-specific antibodies were purchased from Biomerieux, and quantified using manufacturer instruction. Briefly, an ELISA assay (data collected with the Multiskan Spectrum; Thermo Scientific, USA), using as target antigens the extracellular domain of the spike protein in the form of a trimer (ELISA tri-S), and the S-Flow assay, which is based on the recognition of SARS-CoV-2 spike protein expressed on the surface of 293T cells (293T-S), were used to quantify SARS-CoV-2-antibody IgG and IgM in sera.

\section{Enzyme-Linked Immunosorbent Assay}

The ELISA protocol was adapted from the previously reported method by Thompson. ${ }^{13}$ Briefly, the concentration of the coated rNPs and sera dilutions for ELISA were optimized using chessboard titration tests. To determine the cutoff values for the ELISAs, the values of the mean of the standard error of the mean (SEM) of sera from healthy individuals were determined. The optimal coating concentration of antigen and optimal plasma dilutions were $0.1 \mu \mathrm{g} / \mathrm{mL}$ and 1:200, respectively. The cutoff values were determined by calculating the mean absorbance at $450 \mathrm{~nm}$ (A450) of the negative sera plus threefold the SEM values, which were 0.5 and 0.99 for IgG and IgM, respectively. Samples were analyzed using an ELISA plate reader, Thermo Scientific, Massachusetts, United States.

\section{Statistical Analysis}

A descriptive analysis to stratify reactive individuals' geographic area of residence, age, sex, vaccination status (vaccinated and unvaccinated), date of collection, and the arrival of samples was performed. All statistical analyses were performed using IBM-SPSS version 25 statistics, USA, except for the $t$-test comparison of the unvaccinated and vaccinated measles groups, which we performed using GraphPad Prism, version 9.2.0, San Diego, CA, USA. $P$-values 
were determined by an unpaired $t$-test, and data were reported as SEM, being considered significant where the $P$-value was $\leq 0.05$. Additional statistical analyses to extrapolate findings to a broader population or ascertain statistical significance were not performed.

\section{Ethical Considerations}

Children's parents and adult patients agreed to the procedure after the informed consent was explained to them prior to blood collection at their respective healthcare facilities. Prior to the commencement of the study, a formal ethics application that included copies of initial consent was submitted to the National Institute for Health Research ethics' committee to request authorization for the use of these samples. The study was approved by the research ethics committee of the National Institute for Health Research (Ref. No. 16/CE/2021).

\section{Results}

\section{Patient Characteristics}

A total of 442 participants met the eligibility criteria (Table 1). The median age was 5.5 years; $52 \%$ of the participants were female, and $48 \%$ were male sex at birth (Table 1). Stored samples were from participants living in 17 provinces. The largest number of participants were from Luanda (37.1\%), following by Huambo (14.0\%), Uíge (10.9\%), Cuanza Sul (7.9\%), Cuando Cubango (6.3\%), Cuanza Norte (5\%), Bengo (3.6\%), Malanje (3.2\%), Húla (9\%), Cunene (2.0\%), Bié $(1.8 \%)$, Zaire (1.8\%), Moxico (1.6\%), Benguela (1.1\%), Cabinda (0.9\%), Lunda Norte $(0.5 \%)$, Namibe $(0.2 \%)$, and Lunda Sul (0\%) (Table 1).

Table I Sociodemographic Characteristics of Unvaccinated and Vaccinated Participants with Blood Specimens Collected from September 2019 to March 2020 and Available for Serologic Testing

\begin{tabular}{|l|c|}
\hline Characteristic & $\begin{array}{c}\text { Participants (n = 442), } \\
\mathbf{n}(\%)\end{array}$ \\
\hline Age median [(IQR), year] & $5.5(0.3-45)$ \\
\hline Sex & $230(52)$ \\
\hline Female & $212(48)$ \\
\hline Male & \\
\hline Geographic area of residence in Angola & $16(3.6)$ \\
\hline Bengo & $5(1.1)$ \\
\hline Benguela & $8(1.8)$ \\
\hline Bié & $4(0.9)$ \\
\hline Cabinda & $28(6.3)$ \\
\hline Cuando Cubango & $22(5)$ \\
\hline Cuanza Norte & $35(7.9)$ \\
\hline Cuanza Sul & $9(2.0)$ \\
\hline Cunene & $92(14.0)$ \\
\hline Huambo & $9(2.0)$ \\
\hline Huíla & \\
\hline
\end{tabular}

(Continued) 
Table I (Continued).

\begin{tabular}{|l|c|}
\hline Characteristic & $\begin{array}{c}\text { Participants (n = 442), } \\
\text { n (\%) }\end{array}$ \\
\hline Luanda & $164(37.1)$ \\
\hline Lunda Norte & $2(0.5)$ \\
\hline Lunda Sul & $0(0.0)$ \\
\hline Malanje & $14(3.2)$ \\
\hline Moxico & $7(1.6)$ \\
\hline Namibe & $1(0.2)$ \\
\hline Uíge & $48(10.9)$ \\
\hline Zaire & $8(1.8)$ \\
\hline
\end{tabular}

\section{Validation of VIDAS ${ }^{\circledR}$ SARS-CoV-2 Test to Ensure Reproducibility}

To validate the test used in this study, our laboratory's negative and positive controls were used. The estimated sensitivities of the VIDAS ${ }^{\circledR}$ SARS-CoV-2 IgG and IgM for the serological diagnostic were assayed and reported as 97.5\% (39 of 40 [95\% CI: 88.4-99.8\%]) and 95.0\% (38 of 40 [95\% CI: 87.5\%-99.1\%]), respectively. Whereas the specificities for IgG and IgM were 100\% (40 of 40 [95\% CI: 98.9\%-100\%]) and 97.5\% (39 of 40 [95\% CI: 97.0\%99.6\%]), respectively (Suppl. Table 1). The prevalence of the disease in the population was determined using the positive predictive value (PPV) and negative predictive value (NPV) on the VIDAS ${ }^{\circledR}$ SARS-CoV-2 IgG and IgM, and the calculation was done with the assumption of 5\% prevalence. PPV and NPV were computed using results obtained from $\geq 7$ days post symptoms onset. The IgG's PPV and NPV were 100\% and 99.3\% [95\% CI: 98.8-99.6], respectively. While the IgM's PPV and NPV were 92.5\% [95\% CI: 63.4\%-98.9\%] and 99.5\% [95\% CI: 99.0-99.7], respectively (Suppl. Table 2). All taken together, our data clearly suggest a low probability of false positives.

\section{Detection of Antibodies Against SARS-CoV-2}

Of the 442 participants who met our study criteria, 204 were seropositive for measles illness, and 40 patients were reactive for SARS-CoV-2, with the age ranging from 3 months to 38 years; and were considered reactive positives. The characteristics of measles patients with SARS-CoV-2-seropositive are shown in Table 2. These are patients that antibodies were close to the threshold of positivity $(>1)$. The majority of these patients were children, accounting $\mathrm{N}=24$ for females, and $\mathrm{N}=16$ for males (Table 2). With regard to the humoral response analysis, there was a significant difference $(p=0.01)$ between the IgG and IgM indexes in the unvaccinated measles patients. Similarly, a significant difference $(p=0.001)$ was also seen between the IgG and IgM indexes in the vaccinated measles patients (Figure 1).

\section{Symptoms Associated with Measles Disease}

Next, we assessed symptoms related to measles in the 40 seropositive SARS-CoV-2 patients. We observed that all 40 reactive positive SARS-CoV-2 patients were experiencing fever, which accounted for $5 \%$ of the adults and $95 \%$ of the children. Symptom of the runny nose was $3.03 \%$ for adults and $96.97 \%$ for children group. Among the 40 reactive positive SARS-CoV-2 patients, $20.59 \%$ of the adults and $79.41 \%$ of the children showed symptoms of cough. Rash was observed in $5.41 \%$ of the adults, and $94.59 \%$ of the children. The clinical sign of conjunctivitis was seen in $22.58 \%$ of the adults and $77.42 \%$ of the children, pneumonia's clinical sign was observed in $44.44 \%$ of the adults and $55.56 \%$ of the children. While all patients (100\%) presented with otitis, and the clinical sign of diarrhea was seen in adults $(50 \%)$ and children (50\%) (Table 3). At least all patients reported one or more measles symptoms of the disease. The main features 
Table 2 Characteristics of Measles Patients with SARS-CoV-2-Seropositive Specimens

\begin{tabular}{|c|c|c|c|c|c|}
\hline \multicolumn{6}{|c|}{ SARS-CoV-2 Antibodies } \\
\hline Participant & Age (Years) & Sex at birth & IgG & IgM & Possible Risk Factors \\
\hline \multicolumn{6}{|l|}{$0-1$ year } \\
\hline I & 0.3 & Female & 0.27 & 1.33 & Not determined \\
\hline 2 & 0.4 & Female & 0.74 & 1.17 & Not determined \\
\hline 3 & 0.6 & Female & 2.02 & 0.25 & Not determined \\
\hline 4 & I & Female & 1.6 & 0.41 & Not determined \\
\hline 5 & I & Male & 1.39 & 0.60 & Not determined \\
\hline 6 & I & Male & 1.79 & 0.37 & Not determined \\
\hline 7 & I & Female & 1.18 & 0.37 & Not determined \\
\hline 8 & I & Male & 2.36 & 0.61 & Not determined \\
\hline 9 & I & Female & 1.16 & 0.30 & Not determined \\
\hline 10 & I & Male & 0.13 & 1.21 & Not determined \\
\hline 11 & I & Male & 0.13 & 1.21 & Not determined \\
\hline 12 & I & Male & 1.8 & 0.00 & Not determined \\
\hline 13 & I & Female & 1.13 & 0.41 & Not determined \\
\hline 14 & I & Male & 1.21 & 0.10 & Not determined \\
\hline 15 & I & Male & 0.10 & 1.45 & Not determined \\
\hline \multicolumn{6}{|l|}{$>\mathrm{I}-5$ years } \\
\hline 16 & 1.8 & Female & 1.5 & 0.50 & Not determined \\
\hline 17 & 3 & Female & 0.27 & 2.28 & Not determined \\
\hline 18 & 4 & Male & 0.29 & 4.31 & Not determined \\
\hline 19 & 4 & Female & 0.51 & 4.63 & Not determined \\
\hline 20 & 4 & Female & 1.29 & 0.58 & Not determined \\
\hline 21 & 4 & Female & 1.03 & 0.00 & Not determined \\
\hline 22 & 4 & Female & 1.92 & 0.68 & Not determined \\
\hline 23 & 5 & Female & 1.36 & 0.27 & Not determined \\
\hline 24 & 5 & Male & 1.36 & 0.22 & Not determined \\
\hline 25 & 5 & Male & 1.60 & 0.18 & Not determined \\
\hline \multicolumn{6}{|l|}{$>5-10$ years } \\
\hline 26 & 6 & Male & 1.33 & 0.16 & Not determined \\
\hline 27 & 9 & Male & 1.39 & 0.00 & Not determined \\
\hline 28 & 9 & Female & 0.34 & 1.41 & Not determined \\
\hline 29 & 9 & Female & 2.61 & 0.11 & Not determined \\
\hline
\end{tabular}

(Continued) 
Table 2 (Continued).

\begin{tabular}{|c|c|c|c|c|c|}
\hline \multicolumn{6}{|c|}{ SARS-CoV-2 Antibodies } \\
\hline Participant & Age (Years) & Sex at birth & IgG & $\operatorname{Ig} M$ & Possible Risk Factors \\
\hline 30 & 9 & Female & 1.70 & 0.29 & Not determined \\
\hline 31 & 10 & Female & 1.43 & 0.40 & Not determined \\
\hline \multicolumn{6}{|c|}{$>10-15$ years } \\
\hline 32 & 11 & Female & 0.81 & 1.43 & Not determined \\
\hline 33 & 13 & Female & 1.57 & 0.40 & Not determined \\
\hline 34 & 14 & Male & 0.16 & 1.35 & Not determined \\
\hline 35 & 15 & Female & 0.29 & 1.46 & \\
\hline 36 & 15 & Male & 1.56 & 0.11 & Not determined \\
\hline 37 & 15 & Male & 1.56 & 0.11 & Not determined \\
\hline 38 & 15 & Male & 1.56 & 0.11 & Not determined \\
\hline \multicolumn{6}{|l|}{$>15$ years } \\
\hline 39 & 18 & Female & 1.17 & 0.06 & Not determined \\
\hline 40 & 38 & Female & 1.25 & 0.77 & Not determined \\
\hline
\end{tabular}

of the clinical signs of SARS-CoV-2-positive patients are described in Table 3. Among the 40 subjects confirmed positive by the ELISA assay, no particular risk factor or recent international travel history seemed to be attributed to these patients. All patients were believed to have measles within a reasonable time frame (1-2 weeks) after specimen collection, which was done from September 2019.

\section{SARS-CoV-2 Seropositive Antibodies in Relation to the Time of Sampling}

We examined whether the cases of reactive positive SARS-CoV-2 patients increased with time to the first reported RTPCR-confirmed SARS-CoV- 2 case in the country. We found a constant increase of cases ( $\mathrm{N}=6$ for each month) after the

Unvaccinated measles

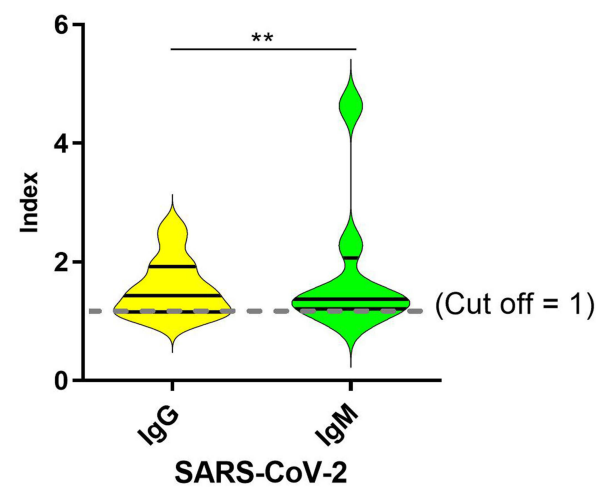

Vaccinated measles

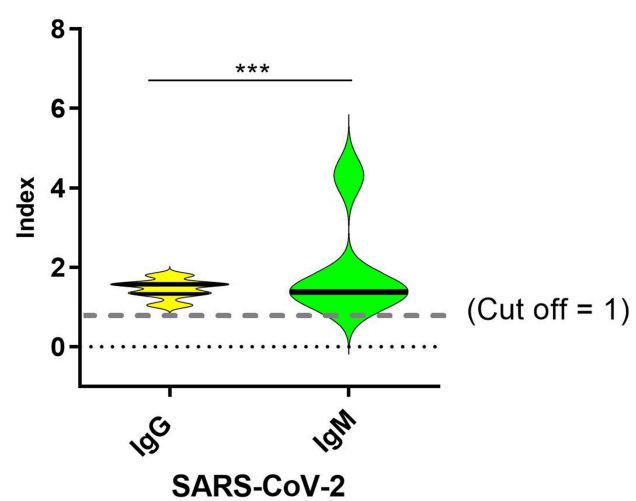

Figure I Test value index between IgG and IgM in the unvaccinated $(\mathbf{A})$ and vaccinated $(\mathbf{B})$ measles patients. Data were reported as standard error of the means. Cut-off value I. $* * P$ value 0.01 and $* * * P$ value 0.001 . Dash line indicates cut-off value $=1$. 
Table 3 Clinical Signs and Symptoms of Disease in All Measles Seropositive Patients and Measles Adults and Children with SARS-CoV-2 Seropositive Blood Specimens

\begin{tabular}{|l|c|c|c|c|c|c|c|c|}
\hline Symptoms & Fever & Runny nose & Cough & Rash & Conjunctivitis & Pneumonia & Otitis & Diarrhea \\
\hline All,N=204(\%) & $40(19.60 \%)$ & $33(16.17 \%)$ & $34(16.67 \%)$ & $37(18.14 \%)$ & $31(15.20 \%)$ & $9(4.41 \%)$ & $4(1.96 \%)$ & $8(3.92 \%)$ \\
\hline Measles and SARS-CoV-2-seropositive patients $(\mathrm{N}=40)$ & & & & \\
\hline Adult & $2(5 \%)$ & $I(3.03 \%)$ & $7(20.59 \%)$ & $2(5.41 \%)$ & $7(22.58 \%)$ & $4(44.44 \%)$ & $0(0.00 \%)$ & $4(50 \%)$ \\
\hline Children & $38(95 \%)$ & $32(96.97 \%)$ & $27(79.41 \%)$ & $35(94.59 \%)$ & $24(77.42 \%)$ & $5(55.56 \%)$ & $4(100 \%)$ & $4(50 \%)$ \\
\hline
\end{tabular}

first month of the initial sampling time (Figure 2). Compared to the initial sampling month, the number of reactive positive SARS-CoV-2 cases doubled ( $\mathrm{N}=8$ in January, and $\mathrm{N}=9$ in February) during the last 2 months of sampling prior to the officially reported first case of SARS-CoV-2 in Angola (Figure 2).

\section{Sex-Dependent Pattern Against Anti-SARS-CoV-2 IgG and IgM Antibodies}

Furthermore, we compared the IgG and IgM reactiveness to SARS-CoV-2 in both males and females, we found that $\mathrm{N}=27(67.5 \%)$ had $\mathrm{IgG}+$, which accounted for $\mathrm{N}=12(44.4 \%)$ of males and $\mathrm{N}=15(55.6 \%)$ of females. Whereas $\mathrm{N}=13$ (32.5\%) patients had $\mathrm{IgM}+$, which accounted $\mathrm{N}=5$ (38.5\%) for males and $\mathrm{N}=8(61.5 \%)$ for female. Among the $\mathrm{N}=27$ patients that produced IgG antibodies against SARS-CoV-2, $\mathrm{N}=12(44.4 \%)$ were male and $\mathrm{N}=15(55.6 \%)$ were female

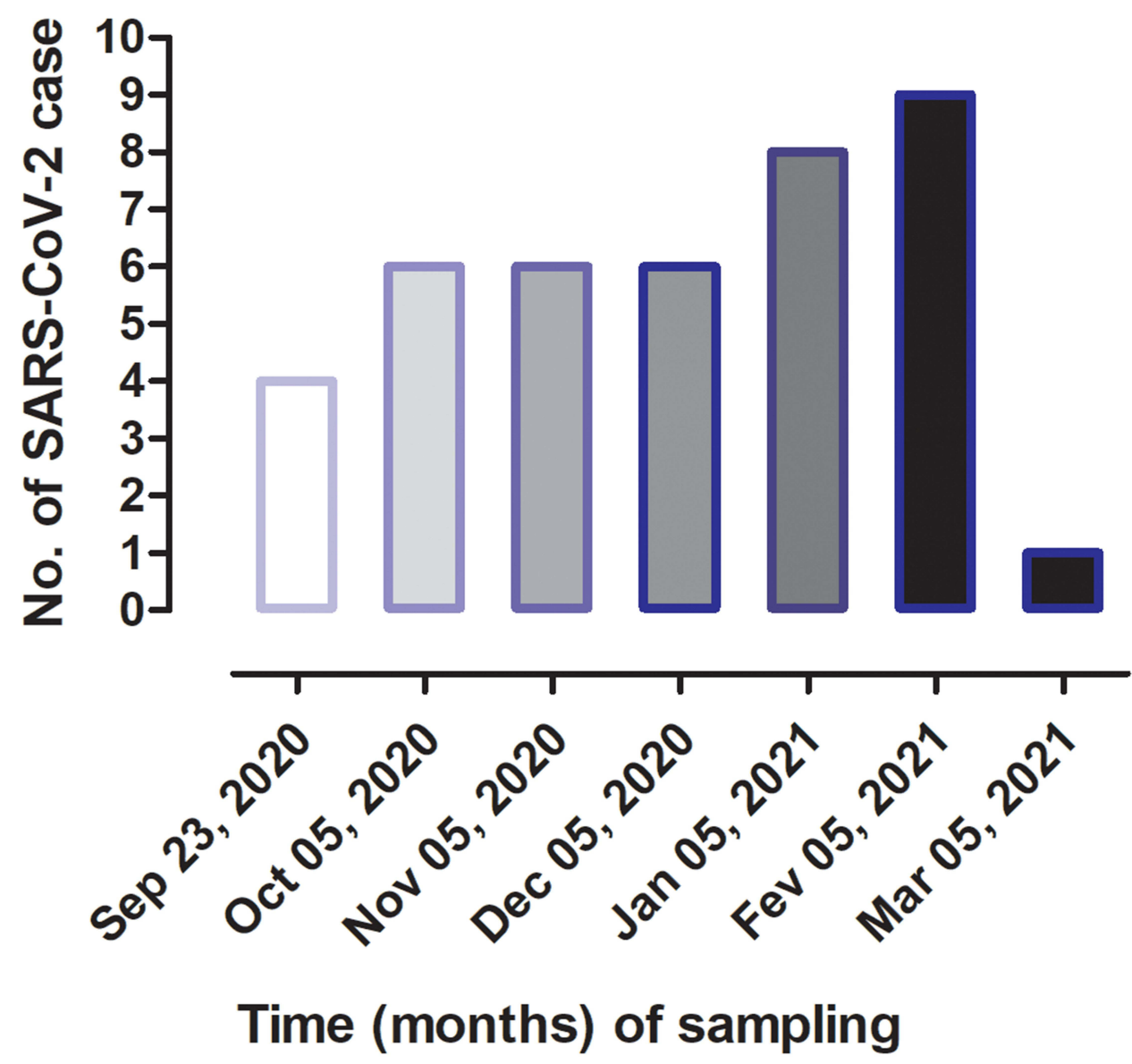

Figure 2 Time-dependent SARS-CoV-2 seropositive antibodies in measles patients, data are presented as number of cases for each sampling month. 
(Table 4). In another hand, $\mathrm{N}=13$ (32.5\%) patients produced IgM antibodies directed to SARS-CoV-2, which accounted for $\mathrm{N}=5$ (38.5\%) for males and $\mathrm{N}=8$ (61.5\%) for females. Among the IgG-positive patients, $\mathrm{N}=9$ patients tested IgMmeasles virus-positive which accounted for $33.3 \%$ of the males and $66.7 \%$ of the females, suggesting that the measles patients were in contact with SARS-CoV-2 (Table 4). To ascertain whether measles patients had SARS-CoV-2 coinfection, we examined the IgM reactive antibodies to SARS-CoV-2 in the measles virus-positive patients $(\mathrm{N}=10)$, data show that $30 \%$ of male and $70 \%$ of the female patients with IgM-measles positive had IgM-SARS-CoV-2 seropositive (Table 4), suggesting that these measles patients also had COVID-19.

\section{Discussion}

This retrospective study on blood specimens from measles patients collected from 23 September 2019 to 28 February 2020, reported from the 17 provinces of Angola, suggests evidence of SARS-CoV-2 infection months before detection of the virus in Luanda, the epicenter of SARS-CoV-2 infection in Angola. Our findings demonstrate that SARS-CoV-2-reactive antibodies were detected in 40 out of 442 specimens, as early as September 23, 2019. Serological detection of IgG and IgM antibodies indicates that the virus that causes COVID-19, may have appeared in Angola earlier than we previously thought. A small portion of the population as indicated from our data may have pre-existing antibodies that bind the SARS-CoV-2 Spike protein, a protein on SARS-CoV-2 that interacts with the human angiotensinconverting enzyme 2 (ACE2) receptor to gain entry into a cell to initiate infection. ${ }^{14-16}$ Similarly, IgG and IgM antibodies to SARS-CoV-2 were detected among patients reporting for measles disease as early as September 2019, in all Angolan provinces, except the province of Lunda Sul. In Angola, the first two SARS-CoV-2 detected were imported positive cases that had traveling history, returning from Portugal.

As the pandemic of COVID-19 has evolved, several tests and techniques for the detection of SARS-CoV-2 have evolved and become available to determine whether an individual may have been in contact with the virus or have an active infection. Previous studies have demonstrated that the median time from IgG antibody reactive to SARS-CoV-2 infection is 14 days. ${ }^{17,18}$ This probably suggests that patients who tested seropositive in our study could have been infected with SARS-CoV-2 weeks earlier. This is possible because of the lack of infrastructure and poor epidemiological vigilance in low-income setting countries. Angola started to perform for the first time, the RT-PCR analysis for SARSCoV-2 testing only in March 2020.

Although the WHO has created mechanisms to sustain the epidemiological surveillance in the low-income setting countries, these countries should have a plan that design strategies for preventing diseases and planning options that contribute to improving the health of the population.

Our finding is the first evidence identifying an early circulation of SARS-CoV-2 in Angola before the first COVID-19 cases were described in China. To the best of our knowledge, this is also the first report from Africa that shows antibody

Table 4 Humoral Responses to SARS-CoV-2 and Coinfection with Measles Virus in Male and Female Blood Specimens

\begin{tabular}{|c|c|c|c|c|}
\hline & \multicolumn{2}{|c|}{ SARS-CoV-2 Antibodies } & & \\
\hline Overall $(N=40)$ & \multicolumn{2}{|c|}{ lgG+ } & \multicolumn{2}{|c|}{ IgM+ } \\
\hline $\mathrm{N}(\%)$ & \multicolumn{2}{|c|}{$27(67.5)$} & \multicolumn{2}{|c|}{$13(32.5)$} \\
\hline \multirow[t]{2}{*}{ Sex } & Male & Female & Male & Female \\
\hline & $12(44.4 \%)$ & $15(55.6 \%)$ & $5(38.5 \%)$ & 8 (6I.5\%) \\
\hline \multicolumn{5}{|c|}{ Coinfection (N=19) } \\
\hline & \multicolumn{2}{|c|}{$\begin{array}{l}\text { IgG-SARS-CoV-2 reactive in } \\
\text { IgM-Measles virus-positive } \\
\text { samples }(\mathrm{N}=9)\end{array}$} & \multicolumn{2}{|c|}{$\begin{array}{l}\text { IgM-SARS-CoV-2 reactive in } \\
\text { IgM-Measles virus-positive } \\
\text { samples }(N=10)\end{array}$} \\
\hline Sex & $3(33.3 \%)$ & $6(66.7 \%)$ & $3(30.0 \%)$ & 7 (70.0\%) \\
\hline
\end{tabular}


evidence of SARS-CoV-2 infection that occurred months before the first confirmed cases. The Angolan Ministry of Health's first report of community transmission of SARS-CoV-2 (those confirmed infections in persons without a travel history) did not occur until 15 July $2020 .{ }^{19}$ Factors that may influence the low spread of SARS-CoV-2 include sociocultural factors, geodemographic and climatic factors. ${ }^{20}$ Many retrospective studies from developed countries have reported the evidence of SARS-CoV-2 spreading nationwide and tested in biological fluid samples, ${ }^{5,6,21,22}$ environment samples ${ }^{10,23}$ and in skin cells ${ }^{24}$ of individuals weeks before the record date.

It is noteworthy that among the 442 individuals reported for measles cases, 40 individuals were seropositive to SARS-CoV-2, distributed in almost all provinces of Angola, except the province of Lunda Sul; with the majority being children (95\%). Evidence from the early phases of the outbreak demonstrated that SARS-CoV-2 pathogenesis in adults varies with age and gender, since older individuals with comorbidities such as cardiovascular disease or diabetes were shown to be at higher risk for developing severe illness from COVID-19. ${ }^{18,25,26}$ Studies by Cruz \& Zeichner and Dong et al using infants and preschool-aged children demonstrated that this at-risk population might be more susceptible to SARS-CoV-2 infection than older children. ${ }^{27,28}$ In contrast, children's pathology is less severe and has a better prognosis after contracting SARS-CoV-2 infection. ${ }^{29}$ Therefore, the significant percentage of SARS-CoV-2-seropositive observed in children could serve as a reservoir of the virus. The reason being that this population group has low morbidity and mortality, and they have also been reported for having fewer underlying medical conditions and healthier respiratory tracts because of less exposure to air pollution, cigarette smoke, finally showing a stronger innate immunity. ${ }^{30}$ In other studies, investigators have found that SARS-CoV-2 infections in children occur in the upper rather than the lower respiratory tract, the typical site of severe COVID-19 disease, where ACE2 receptors are more abundant, ${ }^{27}$ and the production of IgG is prominent. ${ }^{31}$

There is a belief among the health professionals that only a single virus that can cause clinical syndrome, ${ }^{32}$ COVID-19 pandemic, should therefore be one of the cases where syndromes due to coinfection may exist. Stephanie et al reported that the coinfection of SARS-CoV-2 and measles morbillivirus in a front-line health worker in Brazil. ${ }^{32}$ Next, we examined the number of patients with measles virus seropositive that had SARS-CoV-2 reactive. Overall, we found 19 individuals with either IgG or IgM SARS-CoV-2 seropositive, which accounted for $\mathrm{N}=9$ individuals with IgG-SARS-CoV-2 reactive in IgM-measles virus-positive samples, among who were $33.3 \%$ were male and $66.7 \%$ female. Also, we found $\mathrm{N}=10$ individuals with IgM-SARS-CoV-2 reactive in IgM-measles virus-positive, which accounted for $30.0 \%$ male and $70.0 \%$ female, indicating that measles coinfected patients had COVID-19; the latter may exacerbate the emergence of measles. ${ }^{33}$ Although symptoms of measles are atypical to COVID-19, proper control and prevention of both measles and COVID-19 require sustained and robust routine immunization programs.

Our data demonstrated that both unvaccinated and vaccinated individuals tested for SARS-CoV-2 seropositive (Figure 1). The differences observed between the IgG and IgM indexes indicate that the IgM antibody response to SARS-CoV-2 occurred earlier and peaked earlier than the IgG antibody response in both unvaccinated and vaccinated patients; also suggest that the measles vaccine does not produce protection against SARS-CoV-2. Some of the factors that may influence the lack of early detection of the SARS-CoV-2 are lack of testing capacity especially in low-income setting countries, and poor epidemiological surveillance. Results from this study and those from others ${ }^{5,6,10,21,23,24}$ should highlight the need for the countries to strengthen health surveillance approaches.

This study has strength as it includes national data (almost all the provinces of Angola), which provides the opportunity to investigate a critical infection time of SARS-CoV-2, that will enable to expand the understanding of the epidemiology of SARS-CoV-2 in Africa in particular, and the world in general, in a longitudinal study with largescale population. The small increase in cases observed for SARS-CoV-2-seropositive in relation to the time of sampling may be due to the fact that children and adolescents are reservoirs for viral infection and have a more diverse antibody repertoire that may confer some protection against SARS-CoV-2; however, view from other studies differs. ${ }^{34,35}$

Nevertheless, our study has some limitations. First, our participants were not confirmed to be infected with SARS-CoV-2 via RT-PCR, GeneXpert, or paired acute-convalescent serum specimens' tests. Second, we did not include potentially asymptomatic individuals and those with subclinical illness who do not seek or were unable to reach the health facilities. Third, it is possible that we have detected preexisting, non-SARS coronavirus antibodies that bind to SARS-CoV-2 nucleocapsid and spike protein in these 40 individuals, which may render these individuals false-positive, ${ }^{4,28,36}$ since measles virus and SARS-CoV-2 have an evolutionary connection, as they share homologous core proteins. ${ }^{37}$ Cross-reactivity may have occurred in this serological test, 
and it is a situation in which a particular antibody reacts to a substance other than its corresponding antigen ${ }^{30,37}$ To ascertain these phenomena in the VIDAS ${ }^{\circledR}$ SARS-CoV-2 IgG and IgM tests, we analyzed our previously confirmed control-positive samples for measles virus $(\mathrm{N}=5)$, mumps virus $(\mathrm{N}=4)$, and rubella virus $(\mathrm{N}=4)$ including HIV $(\mathrm{N}=10)$ for SARS-CoV-2 IgG and IgM antibodies; none of the samples from these groups were SARS-CoV-2 seropositive (data not shown). This provided further supporting evidence that it is unlikely that all 40 SARS-CoV-2 seropositive individuals were false-positives, as also demonstrated in the sensitivity and specificity data (Suppl. Table 1). Our results are in agreement with those ${ }^{10,38}$ that used antibodies testing to detect the early circulation of SARS-CoV-2, demonstrating the importance of anti-SARS-CoV-2 antibodies testing in the control and surveillance of infection. Therefore, preventative strategies are crucial to minimizing the development and spread of infections.

\section{Conclusion}

Our study reports the first evidence of early circulating SARS-CoV-2 in Angola weeks before the first reported cases of SARS-CoV-2 infection and highlights the importance of implementing sustainable public health surveillance testing strategies in diverse retrospective cohort population studies that can enable to timely inform the entrance of SARS-CoV- 2 .

\section{Acknowledgments}

The authors would like to sincerely thank all the full-time and part-time employees of the National Institute for Health Research for continuous support.

\section{Author Contributions}

All authors made a significant contribution to the work reported, whether that was in the conception, study design, execution, acquisition of data, analysis, and interpretation. All took part in drafting, revising, or critically reviewing the article; also, gave final approval of the version to be published; all have agreed on the journal to which the article has been submitted, and finally agreed to be accountable for all aspects of the work.

\section{Funding}

This study was funded as a donation from the Ministry of Health, Angola.

\section{Disclosure}

The authors declare no conflicts of interest in this work.

\section{References}

1. WHO. World Health Organization, Novel Coronavirus (2019-nCoV) Situation Report - 121 January 2020; 2020: 1-5.

2. Andersen KG, Rambaut A, Lipkin WI, Holmes EC, Garry RF. The proximal origin of SARS-CoV-2. Nat Med. 2020;26(4):450-452.

3. van Dorp L, Acman M, Richard D, et al. Emergence of genomic diversity and recurrent mutations in SARS-CoV-2. Infect Genetics Evol. 2020;83:104351.

4. Okba NMA, Muller MA, Li W, et al. Severe acute respiratory syndrome Coronavirus 2-specific antibody responses in coronavirus disease patients. Emerg Infect Dis. 2020;26(7):1478-1488.

5. Deslandes A, Berti V, Tandjaoui-Lambotte Y, et al. SARS-CoV-2 was already spreading in France in late December 2019. Int J Antimicrob Agents. 2020;55(6):106006.

6. Basavaraju SV, Patton ME, Grimm K, et al. Serologic testing of US blood donations to identify severe acute respiratory syndrome Coronavirus 2 (SARS-CoV-2)-Reactive Antibodies: December 2019-January 2020. Clin Infect Dis. 2021;72(12):e1004-e9.

7. Sebastiao CS, Neto Z, Martinez P, et al. Sociodemographic characteristics and risk factors related to SARS-CoV-2 infection in Luanda, Angola. PLoS One. 2021;16(3):e0249249.

8. Arons MM, Hatfield KM, Reddy SC, et al. Presymptomatic SARS-CoV-2 infections and transmission in a skilled nursing facility. $N$ Engl $J$ Med. 2020;382(22):2081-2090.

9. Carrat F, Figoni J, Henny J, et al. Evidence of early circulation of SARS-CoV-2 in France: findings from the population-based "CONSTANCES" cohort. Eur J Epidemiol. 2021;36(2):219-222.

10. La Rosa G, Mancini P, Bonanno Ferraro G, et al. SARS-CoV-2 has been circulating in northern Italy since December 2019: evidence from environmental monitoring. Sci Total Environ. 2021;750:141711. doi:10.1016/j.scitotenv.2020.141711

11. Althoff KN, Schlueter DJ, Anton-Culver H, et al. Antibodies to SARS-CoV-2 in all of US research program participants, January 2-March 18, 2020. Clin Infect Dis. 2021. doi:10.1093/cid/ciab519. 
12. Worobey M, Watts TD, McKay RA, et al. 1970s and 'Patient 0' HIV-1 genomes illuminate early HIV/AIDS history in North America. Nature. 2016;539(7627):98-101.

13. Thompson R. Pandemic potential of 2019-nCoV. Lancet Infect Dis. 2020;20(3):280.

14. Holshue ML, DeBolt C, Lindquist S, et al. First case of 2019 novel coronavirus in the United States. N Engl J Med. 2020;2020:929-936.

15. Arbeitman CR, Rojas P, Ojeda-May P, Garcia ME. The SARS-CoV-2 spike protein is vulnerable to moderate electric fields. Nat Commun. 2021;12 (1):5407.

16. Zhang Z, Zheng Y, Niu Z, et al. SARS-CoV-2 spike protein dictates syncytium-mediated lymphocyte elimination. Cell Death Differ. 2021;28 (9):2765-2777.

17. Guo L, Ren L, Yang S, et al. Profiling early humoral response to diagnose novel Coronavirus Disease (COVID-19). Clin Infect Dis. 2020;71 (15):778-785.

18. Zhao J, Yuan Q, Wang H, et al. Antibody Responses to SARS-CoV-2 in patients with novel coronavirus disease 2019. Clin Infect Dis. 2020;71 (16):2027-2034.

19. MINSA. Marcos da Resposta em Angola. Direcção nacional de saúde pública; 2021.

20. Admou B, Hazime R, Brahim I, El Adib AR. Influencing factors of SARS-Cov2 spread in Africa. J Glob Health. 2020;10(2):020331.

21. Apolone G, Montomoli E, Manenti A, et al. Unexpected detection of SARS-CoV-2 antibodies in the prepandemic period in Italy. Tumori. 2020;2020:300891620974755.

22. Chapleau RR, Christian M, Connors B, et al. Early identification of SARS-CoV-2 emergence in the department of defense via retrospective analysis of 2019-2020 upper respiratory illness samples. Msmr. 2021;28(6):2-5.

23. Prado T, Fumian TM, Mannarino CF, Maranhao AG, Siqueira MM, Miagostovich MP. Preliminary results of SARS-CoV-2 detection in sewerage system in Niteroi municipality, Rio de Janeiro, Brazil. Mem Inst Oswaldo Cruz. 2020;115:e200196.

24. Cazzato G, Foti C, Colagrande A, et al. Skin manifestation of SARS-CoV-2: the Italian experience. J Clin Med. 2021;10:8.

25. Chen N, Zhou M, Dong X, et al. Epidemiological and clinical characteristics of 99 cases of 2019 novel coronavirus pneumonia in Wuhan, China: a descriptive study. The Lancet. 2020;395(10223):507-513.

26. Huang C, Wang Y, Li X, et al. Clinical features of patients infected with 2019 novel coronavirus in Wuhan, China. The Lancet. 2020;395 (10223):497-506

27. Cruz AT, Zeichner SL. COVID-19 in children: initial characterization of the pediatric disease. Pediatrics. 2020;145:6.

28. Dong Y, Mo X, Hu Y, et al. Epidemiology of COVID-19 among children in China. Pediatrics. 2020;145:6.

29. Ludvigsson JF. Systematic review of COVID-19 in children shows milder cases and a better prognosis than adults. Acta Paediatr. 2020;109 (6): 1088-1095.

30. Lee PI, Hu YL, Chen PY, Huang YC, Hsueh PR. Are children less susceptible to COVID-19? Journal of microbiology. Immunol Infection/Wei Mian Yu Gan Ran Za Zhi. 2020;53(3):371-372.

31. Renegar KB, Small PA Jr, Boykins LG, Wright PF. Role of IgA versus IgG in the control of influenza viral infection in the murine respiratory tract. J Immunol. 2004;173(3):1978-1986.

32. Nascimento J, Castro RRT, Nascimento J, Knoploch BB, Duque P, Neves MAO. Coinfection of SARS-CoV-2 and measles morbillivirus in a front-line health worker in Rio de Janeiro, Brasil. Rev Assoc Med Bras. 2020;66(8):1027-1029.

33. Alobo M. Strengthened health systems are needed to tackle COVID-19 in Africa. Nat Med. 2021;27(7):1126-1127.

34. Huang AT, Garcia-Carreras B, Hitchings MDT, et al. A systematic review of antibody mediated immunity to coronaviruses: kinetics, correlates of protection, and association with severity. Nat Commun. 2020;11(1):4704.

35. Ng KW, Faulkner N, Cornish GH, et al. Preexisting and de novo humoral immunity to SARS-CoV-2 in humans. Science. 2020;370 (6522):1339-1343.

36. Patel EU, Bloch EM, Clarke W, et al. Comparative performance of five commercially available serologic assays to detect antibodies to SARS-CoV2 and identify individuals with high neutralizing titers. J Clin Microbiol. 2021;59:2.

37. Saad M, Elsalamony R. Measles vaccines may provide partial protection against COVID-19. Int J Cancer Biomed Res. 2020;5(1):14-19.

38. Ogata AF, Cheng CA, Desjardins M, et al. Circulating SARS-CoV-2 vaccine antigen detected in the plasma of mRNA-1273 vaccine recipients. Clin Infect Dis. 2021. doi:10.1093/cid/ciab465

\section{Publish your work in this journal}

Infection and Drug Resistance is an international, peer-reviewed open-access journal that focuses on the optimal treatment of infection (bacterial, fungal and viral) and the development and institution of preventive strategies to minimize the development and spread of resistance. The journal is specifically concerned with the epidemiology of antibiotic resistance and the mechanisms of resistance development and diffusion in both hospitals and the community. The manuscript management system is completely online and includes a very quick and fair peer-review system, which is all easy to use. Visit http://www.dovepress.com/testimonials.php to read real quotes from published authors.

Submit your manuscript here: https://www.dovepress.com/infection-and-drug-resistance-journal 